\title{
Methodology to Prioritize Chilean Tailings Selection, According to Their Potential Risks
}

\author{
Elizabeth J. Lam ${ }^{1, *}$, Italo L. Montofré ${ }^{2,3, *}$, Fernando A. Álvarez ${ }^{2,4}$, Natalia F. Gaete ${ }^{1}$, \\ Diego A. Poblete ${ }^{1(1)}$ and Rodrigo J. Rojas ${ }^{1}$ \\ 1 Chemical Engineering Department, Universidad Católica del Norte, Antofagasta CP 1270709, Chile; \\ natalia.gaete.r@gmail.com (N.F.G.); diego.poblete@ucn.cl (D.A.P.); rrojas02@ucn.cl (R.J.R.) \\ 2 Mining Business School, ENM, Universidad Católica del Norte, Antofagasta CP 1270709, Chile; \\ falvarez@ucn.cl \\ 3 Mining and Metallurgical Engineering Department, Universidad Católica del Norte, \\ Antofagasta CP 1270709, Chile \\ 4 Administration Department, Universidad Católica del Norte, Antofagasta CP 1270709, Chile \\ * Correspondence: elam@ucn.cl (E.J.L.); imontofre@ucn.cl (I.L.M.)
}

Received: 22 April 2020; Accepted: 28 May 2020; Published: 2 June 2020

\begin{abstract}
For centuries, Chile has been a territory with significant mining activity, resulting in associated social benefits and impacts. One of the main challenges the country faces today is the presence of a great number of mine tailings containing heavy metals, such as $\mathrm{Cu}, \mathrm{Cr}, \mathrm{Ni}, \mathrm{Zn}, \mathrm{Pb}, \mathrm{As}$, $\mathrm{Cd}$, and $\mathrm{Fe}$, which make up a potential risk for the population. This study is intended to develop a methodology for determining tailings requiring urgent treatment in Chile, based on risks associated with heavy metals. Geochemical data from 530 Chilean tailings were compared to the Dutch norm and the Canadian and Australian soil quality guidelines for residential use. Additionally, criteria about residents and water bodies were used, considering a 2-km area of influence around tailings. To do this, QGIS (Böschacherstrasse 10a CH-8624 Grüt (Gossau ZH), Zurich, Switzerland), a geospatial tool, was used to geolocate each deposit, considering regions, communes, rivers, lakes, and populated areas. To evaluate potential ecological contamination risks, Hakanson's methodology was used. Results revealed the presence of 12 critical tailings in Chile that require urgent treatment. From the 530 tailings evaluated, 195 are located at less than $2 \mathrm{~km}$ from a populated area and 154 at less than $2 \mathrm{~km}$ from a water body. In addition, 347 deposits require intervention: 30 on $\mathrm{Cu}, 30$ on $\mathrm{Cr}, 13$ on $\mathrm{Zn}$, 69 on $\mathrm{Pb}, 138$ on As, 1 on $\mathrm{Cd}$, and 5 on $\mathrm{Hg}$.
\end{abstract}

Keywords: mine tailings; environmental liabilities; mining industries; environmental risks

\section{Introduction}

Chile is recognized for exploiting its mineral resources [1] on a world basis, a fact that has brought about economic benefits, but at the same time, a negative impact on the environment, one of the most severe being the generation of mining environmental liabilities (MEL) [2,3]. These are distributed along the country; some of them are abandoned and without due management and maintenance. According to a survey made in 2017 by the National Geology and Mining Service (SERNAGEOMIN, for its acronym in Spanish) [4], there are 740 tailings in Chile: $14.1 \%$ of them are classified as active, $62.6 \%$ as inactive (non-abandoned), and $23.3 \%$ as abandoned (inactive). From the three groups, the latter requires the most attention, their management being still uncertain since they are not thoroughly characterized. For this reason, three management alternatives are considered: (1) Recovering metals of interest, mainly from old deposits with high mineral grades, which could be further exploited since current technology can help extract more minerals from them [5-7]; (2) utilizing technological solutions for reusing tailings, e.g., as construction aggregates [8]; (3) tailings disposal in a stable manner [9]. 
A high percentage of tailings are old [10]. Their construction was not subjected to state supervision owing to the lack of regulations, thus representing an even greater risk [9]. In the last decade, although Chile has gradually increased its mining regulatory framework to benefit the environment, there are still serious weaknesses. The Chilean territory is characterized by different types of climates and soils [11], thus making background metal concentrations quite different from each other in the different regions. On a national basis, there is a scarce amount of background metal concentrations. This has not allowed the establishment of regulations to assess the risks that the concentration of certain substances in the soil could imply. So, international regulations are used, resulting from the natural soil conditions of foreign countries. Considering that Chile shows a geological soil diversity and a natural mineralogical abundance, the uncertainty concerning the use of these adopted regulations is high. In 2012, the Chilean Ministry of Environment approved the Methodological Guide for Managing Soils with Potential Presence of Contaminants (GMPGSPPC, for its acronym in Spanish) [12].

In developed countries such as The Netherlands, Canada, and Australia, the establishment of reference values for heavy metals in soils has allowed the improvement of their planning and environmental management, thus becoming a control device for environmental entities. Since Chile does not count on these reference values, although it does have a large amount of soils with a potential presence of contaminants, mainly from mine tailings, the country needs a methodology to estimate the priority to intervene in the sites exposed to them.

Risks associated with tailings are critical because the latter are large masses that could suffer physical and/or chemical destabilizations, that is, the collapse or overflow of the solid materials in the dam, along with chemical reactions resulting in acid mining drainage [13-15]. Thus, tools to create a record of tailings requiring intervention is urgently needed. Health risks associated with mineral exposures are widely reported in the literature. Particularly, early exposure to tailings has been associated with the prevalence of congenital malformations, diarrhea, asthma, endocrine and neurological disorders, among others, neurodevelopmental delays and deficits, obesity, diabetes, and cancer-some of which have been increasing over the last few decades [16,17].

The objective of the study is to estimate whether Chilean tailings involve contamination risks. To do this, an applied methodology combining the use of algebraic equations and international reference values with environmental and demographic criteria related to the environmental risk stated in GMPGSPPC is presented. Finally, an assessment of the potential ecological risk resulting from heavy metal contamination is made by using Hakanson's methodology [18], which was chosen because it is one of the methods widely used to assess the potential ecological risks of mining soils [19-25]. This methodology allowed the creation of a record of Chilean tailings to be prioritized for urgent intervention, control, and management.

\section{Materials and Methods}

\subsection{Experimental Data}

Experimental data were obtained from the geochemical database of the Chilean Geochemical Characterization Program for tailings from SERNAGEOMIN [4]. The data corresponded to 631 out of the 740 tailings registered in the country. The characterization involved the measurement of concentrations in $\mathrm{g} \mathrm{ton}^{-1}$ of 56 elements and species per sample, considering potential risks and economic values associated with elements of value. Other data available in the database were the type of mining originating the tailings, the state of the tailings (active, inactive, abandoned), their location (region, commune, and geographic coordinates), and mass in estimated tons. These data are available only for a small number of deposits.

Eight elements and species characterized in the sample were evaluated: $\mathrm{As}, \mathrm{Cd}, \mathrm{Cr}, \mathrm{Cu}, \mathrm{Fe}$, $\mathrm{Ni}, \mathrm{Pb}$, and $\mathrm{Zn}$. In this study, the geochemical data identification number (IDQ), provided by the SERNAGEOMIN database aforementioned, was used for each measurement to identify tailings. Only 530 from the 631 dams had georeferentiation data, so 530 dams were assessed. 


\subsection{Tailings Characteristics}

From the 530 tailings, 84 were classified as active, 421 as inactive, and 25 as abandoned. On a regional basis, most tailings were found in the Coquimbo region (62\%), the Atacama region (19\%), and the Antofagasta region (6\%).

According to the type of mining originating them, the following tailings were found: $\mathrm{Ag}-\mathrm{Au}$ (2), $\mathrm{Au}$ (66), $\mathrm{Au}-\mathrm{Cu}$ (15), $\mathrm{Au}-\mathrm{Cu}-\mathrm{Ag}$ (11), $\mathrm{Au}-\mathrm{Zn}$ (2), $\mathrm{Cu}$ (193), $\mathrm{Cu}-\mathrm{Au}$ (99), $\mathrm{Cu}-\mathrm{Mo}$ (13), $\mathrm{Cu}-\mathrm{Au}-\mathrm{Ag}(1)$, $\mathrm{Cu}-\mathrm{Au}-\mathrm{Fe}(1), \mathrm{Fe}(4), \mathrm{Zn}(2), \mathrm{Zn}-\mathrm{Cu}(2)$, limestone (2), sediment (96), unknown origin (8), and extremely old dams or stockpiles (2).

\subsection{Methodology}

Figure 1 shows the methodology proposed, which consists of three phases. Phase 1: Identifying tailings exceeding the admissibility of the reference concentration values of $\mathrm{As}, \mathrm{Cd}, \mathrm{Cr}, \mathrm{Cu}, \mathrm{Fe}, \mathrm{Ni}, \mathrm{Pb}$, and Zn from the Canadian [26] and Australian [27] guidelines and the Dutch norm [28]. These countries were chosen for the following reasons: (1) The Netherlands is considered as the country with the most experience and development for protecting soil contamination, their norm being the most used in different parts of the world that lack reference values [29-31]; (2) Canadian standard values have been used as a reference for soil quality in Chile [9,12]; (3) Australia has climatic and geological characteristics quite similar to Chile [32]. This phase provided a record of tailings whose heavy metal concentration exceeded the values of the three international reference guidelines.

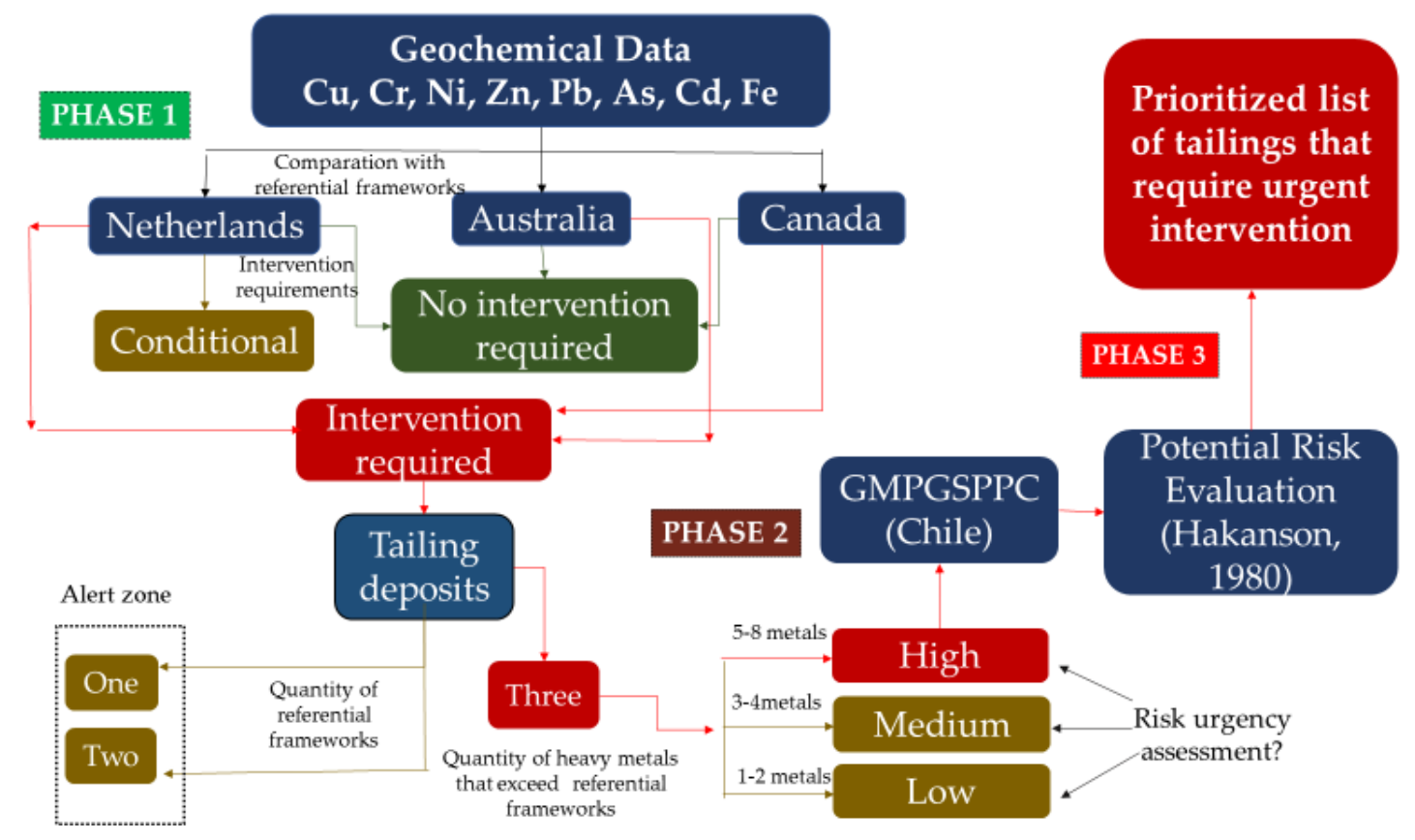

Figure 1. Description of the methodology.

Phase 2: The tailings identified in Phase 1 were assessed according to two of the priority criteria established in GMPGSPPC [12]. This phase allowed us to obtain a record of the tailings representing a higher risk for the health and safety of the population around them. A subrecord of the tailings identified in Phase 1 was obtained, also including criteria considered as a priority for Chile. Phase 3: The potential risk of deposits showing heavy metal concentrations over reference values, which were also considered as critical in Phase 2, according to the evaluation of risk for health and safety, was estimated by using the methodology by Hakanson [18], who defined mathematical equations and parameters to estimate contaminant-potential and the ecological risk of different heavy metals. 
The results allowed us to obtain a subrecord from the one obtained in Phase 2, which identifies Chilean tailings requiring urgent intervention.

The methodology followed for each phase shown in Figure 1 is described below.

2.3.1. Phase 1: Comparison of Heavy Metal Concentrations, Using International Reference Values

\section{Reference Frameworks}

The geochemical data of tailings were compared with the standard values of soils used by the population, established by the Canada Soil Quality Guidelines [26], the Australian guidelines [27], and the standards established by the Ministry of Infrastructure and Water Management (MIWM) in the Dutch Soil Regulation Circular [28].

- Canadian and Australia Guidelines

Given the great variability of reference concentration values provided by the Canadian and Australian guidelines, the first parametrization was made by using the equation by Esquenazi et al. [9]:

$$
C^{*}=\operatorname{sign}(C) \cdot \log [1+\operatorname{abs}(C)]
$$

where $C$ is the concentration of the element or substance, and $C^{*}$ is the corresponding parameterized value. The Canadian and Australian parameterized values for industrial use are shown in Table 1. The experimental values of heavy metal concentrations corresponding to the 530 tailings assessed were also parameterized with Equation (1). Then, they were compared with the reference values in Table 1.

Table 1. Canadian [26] and Australian [27] soil quality reference values.

\begin{tabular}{ccccc}
\hline Parameter & \multicolumn{2}{c}{ Canada } & \multicolumn{2}{c}{ Australia } \\
\hline & Real Value $^{\mathbf{1}}$ & Parameterized Value $^{\mathbf{1 , 2}}$ & Real Value $^{\mathbf{1}}$ & Parameterized Value $^{\mathbf{1 , 2}}$ \\
\hline \multicolumn{5}{c}{ g ton $^{-1}$} \\
$\mathrm{As}$ & 12 & 1.1139 & 100 & 2.0043 \\
$\mathrm{Cd}$ & 10 & 1.0414 & 20 & 1.3222 \\
$\mathrm{Cr}$ & 64 & 1.8129 & 100 & 2.0043 \\
$\mathrm{Cu}$ & 63 & 1.8062 & 1000 & 3.0004 \\
$\mathrm{Hg}$ & 6.6 & 0.8808 & 15 & 1.2041 \\
$\mathrm{Ni}$ & 45 & 1.6628 & 600 & 2.7789 \\
$\mathrm{~Pb}$ & 140 & 2.1492 & 300 & 2.4786 \\
$\mathrm{Zn}$ & 250 & 2.3997 & 7000 & 3.8452 \\
\hline
\end{tabular}

${ }^{1}$ Soils for residential use. ${ }^{2}$ Parameterization with Equation (1).

- $\quad$ Dutch norm

The Dutch norm is based on an algebraic formula that allows the adaptation of its use, depending on soil nature. Its parameters include the standard intervention value (SIV), which depends on two parameters characteristic of the soil: the percentage of organic material weight and the percentage of clay weight. Although this norm does not have a legal value in Chile, it has been the reference most frequently used by SERNAGEOMIN so far, the same as in other countries [33-36]. Since the SERNAGEOMIN geochemical database does not include the measurement of clay percentage nor the percentage of organic material, the Dutch norm adapted to mine tailings by Esquenazi et al. [9] was used. This methodology allows the definition of risk zones for the population and/or the environment by means of three criteria: (1) intervention required, (2) conditional intervention required, and (3) no intervention required [9].

The soil intervention value (SIV) is defined by Equation (2):

$$
\mathrm{SIV}=\operatorname{SSIV} \cdot \frac{\mathrm{A}+\mathrm{B} \cdot \mathrm{x}_{\mathrm{C}}+\mathrm{B} \cdot \mathrm{x}_{\mathrm{OM}}}{\mathrm{A}+25 \cdot \mathrm{B}+10 \cdot \mathrm{C}}
$$


where $\mathrm{A}, \mathrm{B}$, and $\mathrm{C}$ are the specific parameters of each metal, and $\mathrm{x}_{\mathrm{OM}}$ and $\mathrm{x}_{\mathrm{C}}$ are the percentage values of organic material and clay weight, respectively. Table 2 shows the values of $A, B$, and $C$ for the eight heavy metals to be assessed, assuming $25 \%$ clay and $10 \%$ organic material. SSIV is the intervention value of a standard soil for residential use, having the following values: As $=27 \mathrm{mg} \mathrm{kg}^{-1} ; \mathrm{Cd}=1.2 \mathrm{mg}$ $\mathrm{kg}^{-1} ; \mathrm{Hg}=0.83 \mathrm{mg} \mathrm{kg}^{-1} ; \mathrm{Pb}=2.10 \mathrm{mg} \mathrm{kg}^{-1} ; \mathrm{Co}=35 \mathrm{mg} \mathrm{kg}^{-1} ; \mathrm{Cu}=54 \mathrm{mg} \mathrm{kg}^{-1} ; \mathrm{Ni}=34 \mathrm{mg} \mathrm{kg}^{-1}$ and $\mathrm{Zn}=200 \mathrm{mg} \mathrm{kg}^{-1}$ [28].

Table 2. Reference values for the SIV calculation of each element, according to the Dutch norm [28].

\begin{tabular}{cccc}
\hline Element & A & B & C \\
\hline $\mathrm{As}$ & 15 & 0.4 & 0.4 \\
$\mathrm{Cd}$ & 0.4 & 0.007 & 0.021 \\
$\mathrm{Hg}$ & 0.2 & 0.0034 & 0.0017 \\
$\mathrm{~Pb}$ & 50 & 1 & 1 \\
$\mathrm{Ni}$ & 10 & 1 & 0 \\
$\mathrm{Zn}$ & 50 & 3 & 1.5 \\
$\mathrm{Cu}$ & 15 & 0.6 & 0.6 \\
$\mathrm{Cr}$ & 50 & 2 & 0 \\
\hline
\end{tabular}

Adjusted threshold values were estimated for each heavy metal $\left(\mathrm{C}_{\mathrm{F}}\right)$ by applying Equation $(3)[9,37]$.

$$
\mathrm{C}_{\mathrm{F}}=\frac{\mathrm{SIV}}{\mathrm{SSIV}} \cdot\left(\frac{\mathrm{A}+25 \cdot \mathrm{B}+10 \cdot \mathrm{C}}{\mathrm{B}}\right)-\frac{(\mathrm{A}+2 \mathrm{C})}{\mathrm{B}}
$$

To simplify the analysis, $C_{F}$ values were parametrized according to the equation by Esquenazi et al. [9], defined as

$$
\mathrm{AC}_{\mathrm{F}}=\operatorname{sign}\left(\mathrm{C}_{\mathrm{F}}\right) \cdot \log \left(1+\operatorname{abs}\left(\mathrm{C}_{\mathrm{F}}\right)\right)
$$

If $\mathrm{AC}_{\mathrm{F}}<0$, no intervention required.

If $\mathrm{AC}_{\mathrm{F}}>2$, intervention required.

If $0<\mathrm{AC}_{\mathrm{F}}<2$, intervention depends on the values of other parameters.

$\mathrm{AC}_{\mathrm{F}}$ are the reference values of the Dutch norm.

Intervention Requirements Due to Contamination

The heavy metal concentration values of the 530 tailings under assessment were parameterized by using Equation (1). These were compared with the Canadian and Australian reference values (Table 1) and the values obtained from the Dutch norm equations (Equations (2)-(4)).

As a result of the three referential frameworks, the "no intervention required" and "intervention required" criteria were obtained. Additionally, in the case of the adapted Dutch methodology, the "conditional intervention" criterion was obtained. Its conditionality is subjected to the availability of the percentage values of organic material and clay in the tailings. These data are not available from the SERNAGEOMIN geochemical database.

The selection of deposits requiring urgent intervention depends on how their concentrations exceed the admissibility indicated by the Canadian and Australian guidelines and the Dutch norm. In this study, the number of metals classified as "intervention required" by the three international reference values was established as an indicator of the initial tailings prioritization. The priority criteria determined in this study were the following: low priority (0-2 metals requiring intervention), medium priority (3-4 metals requiring intervention), and high priority ( 5 or more metals requiring intervention). 
2.3.2. Phase 2: Prioritization Criteria, According to the Methodological Guidelines for Soils with the Potential Presence of Contaminants

Once the tailings were classified according to the intervention prioritization described above, a geospatial tool, QGIS, was used and added to the geographic data layers present in Chilean databases to determine their location. To prioritize soils with potential presence of contaminants (SPPC), two out the four criteria indicated by the methodological guidelines approved by the Chilean Ministry of Health to manage them were used [10]. The objective of these guidelines is to prioritize SPPC, as follows:

Distance from tailings to a populated area: less than $2 \mathrm{~km}-$ "high priority", 2-3 km-“medium priority", and greater than $3 \mathrm{~km}$ - "low priority".

Closeness to water bodies: If tailings are close to water bodies, they are considered as "high priority". If not, they are considered as "low priority".

Table 3 shows the criteria for classifying Chilean tailings priority. The prioritization criterion "extreme" was applied to tailings with two or more red boxes, without disregarding the case of one red box, which also requires "high priority".

Table 3. Criteria for classifying tailings priority requirements.

\begin{tabular}{|c|c|c|c|c|c|c|c|c|}
\hline \multirow{2}{*}{$\begin{array}{c}\text { Prioritized } \\
\text { Intervention } \\
\text { Requirements }\end{array}$} & \multicolumn{3}{|c|}{ Closeness to Communities } & \multicolumn{3}{|c|}{$\begin{array}{l}\text { Metal Concentration over } \\
\text { Reference Values }{ }^{1}\end{array}$} & \multicolumn{2}{|c|}{$\begin{array}{l}\text { Closeness to } \\
\text { Water Bodies }\end{array}$} \\
\hline & $<2 \mathrm{~km}$ & $2-3 \mathrm{~km}$ & $>3 \mathrm{~km}$ & $0-2$ & $3-4$ & $5-8$ & Yes & No \\
\hline \multicolumn{9}{|l|}{ High } \\
\hline \multicolumn{9}{|l|}{ Medium } \\
\hline Low & & & & & & & & \\
\hline
\end{tabular}

\subsubsection{Phase 3: Potential Risk Estimation}

Lastly, the potential environmental risk of tailings identified as the most critical in the previous phases was estimated. To estimate potential tailings, Hakanson's methodology [18] was used. He defined mathematical equations and parameters to estimate potential contaminants and the ecological risk factors of various heavy metals. Hakanson proposed the "Potential Ecological Risk Index" (PERI) as a quick tool for environmental assessment, resulting in the classification of contamination areas and the identification of toxic substances of interest. PERI provides a simple quantitative method for assessing the ecological risk potential of a contamination situation [38]. The equations used are the following [39]:

$$
\mathrm{C}_{\mathrm{f}}^{\mathrm{i}}=\mathrm{C}^{\mathrm{i}} / \mathrm{C}_{\mathrm{n}}^{\mathrm{i}}
$$

where $C_{f}^{i}$ is the contaminant factor of heavy metals " $i$ ", $C^{i}$ is heavy metal concentration, and $C_{n}^{i}$ represents the heavy metal concentration in a nearby area without anthropogenic intervention (background level). $\mathrm{E}_{\mathrm{r}}^{\mathrm{i}}$ is the ecological risk factor defined as

$$
E_{r}^{i}=T_{r}^{i} * C_{f}^{i}
$$

$\mathrm{T}_{\mathrm{r}}^{\mathrm{i}}$ is the heavy metal toxicity factor. The values of the heavy metal toxicity factors, $\mathrm{T}_{\mathrm{r}}^{\mathrm{i}}$, were $\mathrm{Hg}$ (40), Cd (30), As (10), Cu (5), Pb (5), Cr (2), Zn (1), and Ni (6) [14,40].

On the basis of contaminant and ecological risk factors, a potential ecological risk index, RI, was determined through the following addition:

$$
\mathrm{RI}=\sum_{\mathrm{i}=1}^{\mathrm{n}} \mathrm{E}_{\mathrm{r}}^{\mathrm{i}}
$$


Equation (7) allows us to estimate the potential ecological risk, considering the criteria in Table 4. [41].

Table 4. Adjusted grading standard of potential ecological risk of heavy metals in soil [41].

\begin{tabular}{cccc}
\hline $\mathrm{E}_{\mathbf{r}}^{\mathrm{i}}$ & Contamination Level & RI & Potential Ecological Risk \\
\hline $\mathrm{E}_{\mathrm{r}}^{\mathrm{i}}<30$ & Low & $\mathrm{RI}<40$ & Low \\
$30 \leq \mathrm{E}_{\mathrm{r}}^{\mathrm{i}}<60$ & Middle & $40 \leq \mathrm{RI}<80$ & Middle \\
$60 \leq \mathrm{E}_{\mathrm{r}}^{\mathrm{i}}<120$ & High & $80 \leq \mathrm{RI}<160$ & High \\
$120 \leq \mathrm{E}_{\mathrm{r}}^{\mathrm{i}}<240$ & Very high & $160 \leq \mathrm{RI}<320$ & Very high \\
$240 \leq \mathrm{E}_{\mathrm{r}}^{\mathrm{i}}$ & Extremely high & $320 \leq \mathrm{RI}$ & Extremely high \\
\hline
\end{tabular}

\section{Results and Discussion}

\subsection{Comparison of Intervention Requirements}

There is a great discrepancy between the criteria of the three references, although all of them consider the soil for "residential" use, thus showing the need to have soil background values. These are scarcely measured in Chile, being a basic disadvantage for developing soil norms in the country.

Table 5 shows the intervention requirements for the 530 tailings assessed, according to the three reference frameworks. Owing to the lack of data about the mass percentage of organic material and clay, there is a great number of tailings classified as "uncertain" (conditional intervention) according to the Dutch norm, thus making assessment difficult. Metals most frequently presenting this characteristic were $\mathrm{Cr}, \mathrm{Cd}$, and $\mathrm{Ni}$, the percentage of "uncertain" being 73.4\%, 77.9\%, and 63.0\%, respectively. The metals from the dams classified as "uncertain", showing the smallest number of "uncertainties", were $\mathrm{Cu}, \mathrm{Hg}, \mathrm{Hg}$, and As, with $11.1 \%, 10.8 \%, 13.0 \%$, and $13.0 \%$, respectively.

Table 5. Results of the Dutch, Australian, and Canadian soil quality reference guidelines application to 530 Chilean tailings.

\begin{tabular}{cccccccccc}
\hline Reference & Requirements & $\mathbf{A s}$ & $\mathbf{C u}$ & $\mathbf{C r}$ & $\mathbf{C d}$ & $\mathbf{N i}$ & $\mathbf{P b}$ & $\mathbf{H g}$ & $\mathbf{Z n}$ \\
\hline \multirow{2}{*}{ Dutch } & Intervention required & 138 & 460 & 34 & 1 & 0 & 89 & 24 & 55 \\
norm & No intervention required & 323 & 11 & 107 & 116 & 196 & 372 & 449 & 325 \\
& Conditional intervention & 69 & 59 & 389 & 413 & 334 & 69 & 57 & 150 \\
\hline Canadian & Intervention required & 0 & 521 & 238 & 37 & 324 & 255 & 29 & 181 \\
guidelines & No intervention required & 530 & 9 & 292 & 493 & 206 & 275 & 501 & 349 \\
\hline Australian & Intervention required & 163 & 347 & 30 & 525 & 0 & 171 & 525 & 13 \\
guidelines & No intervention required & 367 & 183 & 500 & 5 & 530 & 359 & 5 & 517 \\
\hline
\end{tabular}

Table 5 also shows that $\mathrm{Cu}$ is the metal requiring the most intervention, according to the three reference guidelines. Based on the reference values of the Dutch, Canadian, and Australian soils, 86.8\%, $98.3 \%$, and $65.5 \%$ of the dams require intervention, respectively.

The Australian reference values are the most demanding for $\mathrm{As}, \mathrm{Cd}$, and $\mathrm{Hg}$, all of them being cancerogenic toxic substances, as shown by the great number of tailings requiring intervention due to the presence of these metals. Since Chile and Australia share similar climates, types of soil, and mining, these values must be considered.

A comparison was made among the results obtained for the three guidelines. Coincidences resulting from "intervention required" and "no intervention required" for the heavy metals assessed are shown in Figure 2. 


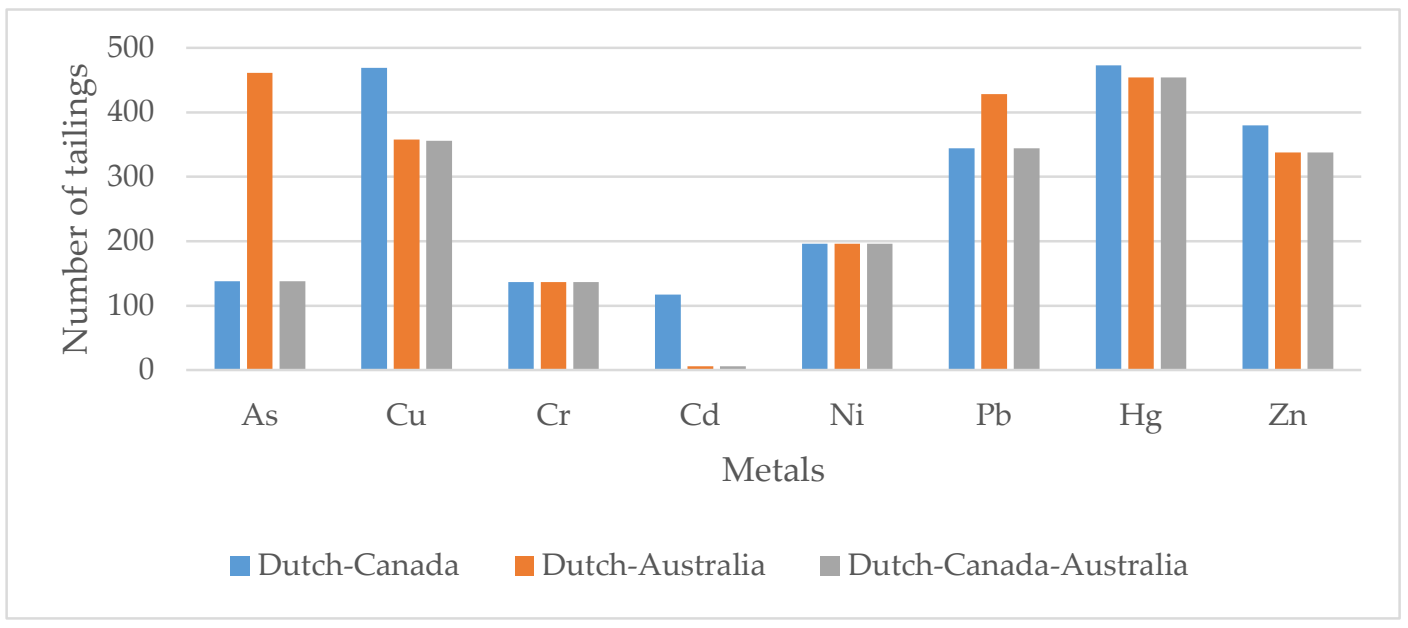

Figure 2. Comparison of results by applying the Canadian and Australian guidelines and the adapted Dutch norm to 530 tailings.

In comparing requirements, there was a good agreement between The Netherlands and Australia $(87.0 \%)$, while the agreement between The Netherlands and Canada amounted to only $26.0 \%$ for this metal. Concerning $\mathrm{Cu}, 67.2 \%$ agreement was found between the three guidelines, while the agreement between The Netherlands and Canada reached $88.5 \%$. As to $\mathrm{Cr}, \mathrm{Cd}$, and $\mathrm{Ni}$, the three guidelines show significant discrepancies, $\mathrm{Cd}$ being the most remarkable because only $1.1 \%$ of the 530 tailings agree with this criterion. The greatest agreement was found for $\mathrm{Hg}$; that is, $85.7 \%$ of the criteria coincided for the three reference frameworks. A good agreement was also found for $\mathrm{Pb}$ and $\mathrm{Zn}$; that is, $64.9 \%$ and $63.8 \%$, respectively.

Table 5 shows a great number of "uncertain" criteria concerning the Dutch norm, thus decreasing the number of comparisons. In the case of $\mathrm{Cr}, \mathrm{Cd}$, and $\mathrm{Ni}$, there are $73.4 \%, 77.9 \%$, and $63.0 \%$ tailings that fit into the category of "uncertain" for these metals, respectively, making the application of the proposed methodology difficult.

In addition, the number of tailings requiring intervention was analyzed for the number of heavy metals exceeding maximum values, according to the three guidelines. As a result, 304 tailings required the intervention of one heavy metal; 117 tailings, two heavy metals; 77 tailings, three heavy metals; 28 tailings, four heavy metals; 4 tailings, five heavy metals, while none of the tailings required the intervention of six or more heavy metals.

The four tailings exceeding the three norms by five heavy metals are considered as "high priority". They were identified by their IDQ geochemical data numbers. One of them is abandoned, while the other three are inactive. All of them contain a number of heavy metals exceeding the reference values of the three guidelines under assessment, that is, five heavy metals. The tailings size ranges from 600 to $1,875,000 \mathrm{t}$. Three of them are located in Sierra Gorda commune (Antofagasta Region) and one in Río Hurtado commune (Coquimbo Region). Table 6 shows their characteristics.

Table 6. Characteristics of the most critical tailings from a risk viewpoint, according to Dutch, Canadian, and Australian reference frameworks.

\begin{tabular}{cccccc}
\hline IDQ & Resource & Mass (t) & State & Region & Commune \\
\hline 1609 & $\mathrm{Cu}$ & $1,875,000$ & Inactive & Antofagasta & Sierra Gorda \\
1665 & $\mathrm{Cu}$ & 600 & Abandoned & Antofagasta & Sierra Gorda \\
1639 & $\mathrm{Cu}$ & 14,080 & Inactive & Antofagasta & Sierra Gorda \\
949 & $\mathrm{Cu}-\mathrm{Au}$ & 40,005 & Inactive & Coquimbo & Río Hurtado \\
\hline
\end{tabular}

In applying the priority criteria mentioned above to the 530 tailings, 32 of them were classified as "high priority"; 195 as "medium priority"; and 303 as "low priority" for heavy metals. Tailings 
presenting the highest risks are located in Coquimbo, Atacama, and Antofagasta regions, an obvious fact since the country's largest mining activity is concentrated in the Chilean northern zone. Figure 3 shows the tailings' regional distribution.

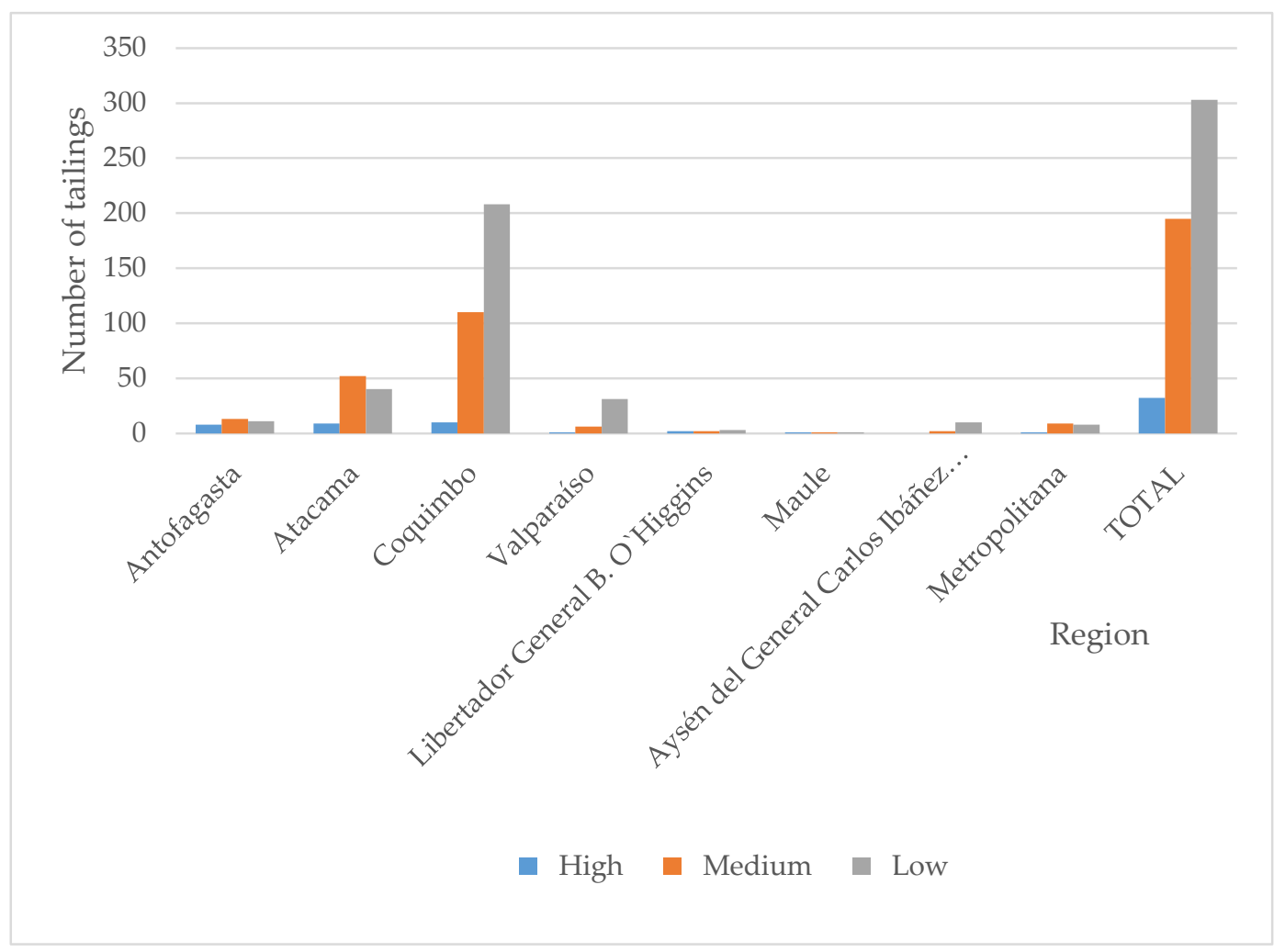

Figure 3. Priority classification of Chilean tailings by region.

\subsection{Chilean Methodological Guideline Application}

To apply the Chilean guidelines, it is first necessary to establish the location of each tailing. To do this, QGIS was used to geolocate them. This was compared with the layers available in the country, considering regions, communes, rivers, lakes, and populated areas.

For geospatial data, a $2-\mathrm{km}$ area of influence was created around the tailings based on data from Census 2012 (Chile, 2012) for the different locations. Figure 4 shows a Coquimbo region map as an example to indicate tailings and populated areas. Figure 4 shows the tailings area of influence of about $2 \mathrm{~km}$ around populated areas.

An analysis of the 530 tailings revealed that 195 and 290 of them are located at 2 and $3 \mathrm{~km}$ from a populated area, respectively. In addition, there are 154 tailings located near rivers, lakes, and estuaries. Their distribution is shown in Figure 5.

The assessment showed that there are 32 tailings classified as "high priority" due to heavy metal concentration, 195 due to closeness to populated areas, and 154 for closeness to water bodies. Figure 6 shows the results of the 530 tailings assessed, according to the number of heavy metals exceeding maximum values and closeness to populated areas by region. Figure 7 shows the results considering heavy metals and closeness to water bodies. Figure 6 shows tailings classified as "extreme"; that is, they present two critical characteristics: (1) the number of heavy metals exceeding maximum reference values is 5 or more, while (2) closeness to populated areas is smaller than $2 \mathrm{~km}$. On the contrary, Figure 7 does not show any "extreme" tailings, indicating that, at the most, the heavy metals exceeding maximum values are 4 . 


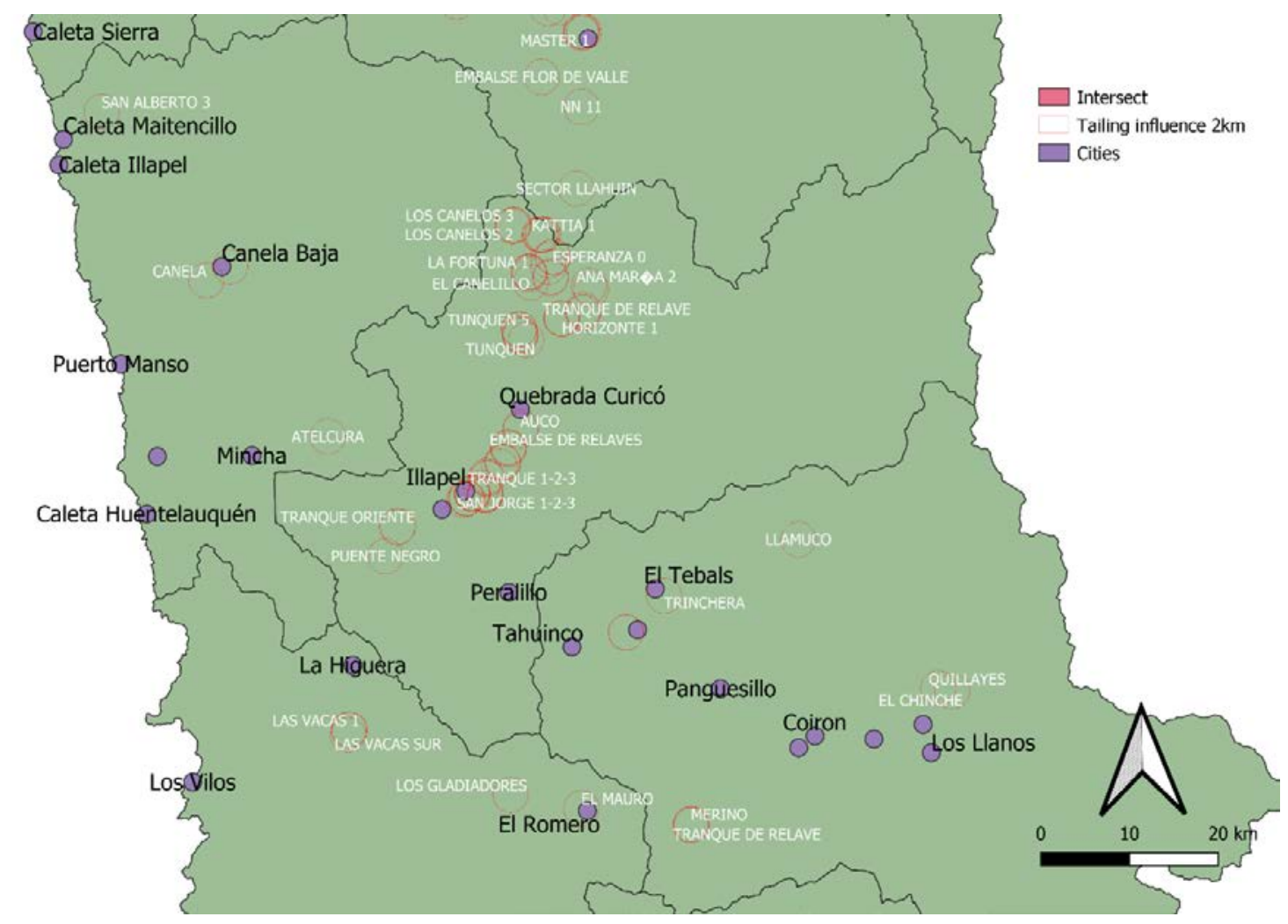

Figure 4. Map of the urban area intersections with tailings distribution in the Coquimbo region.

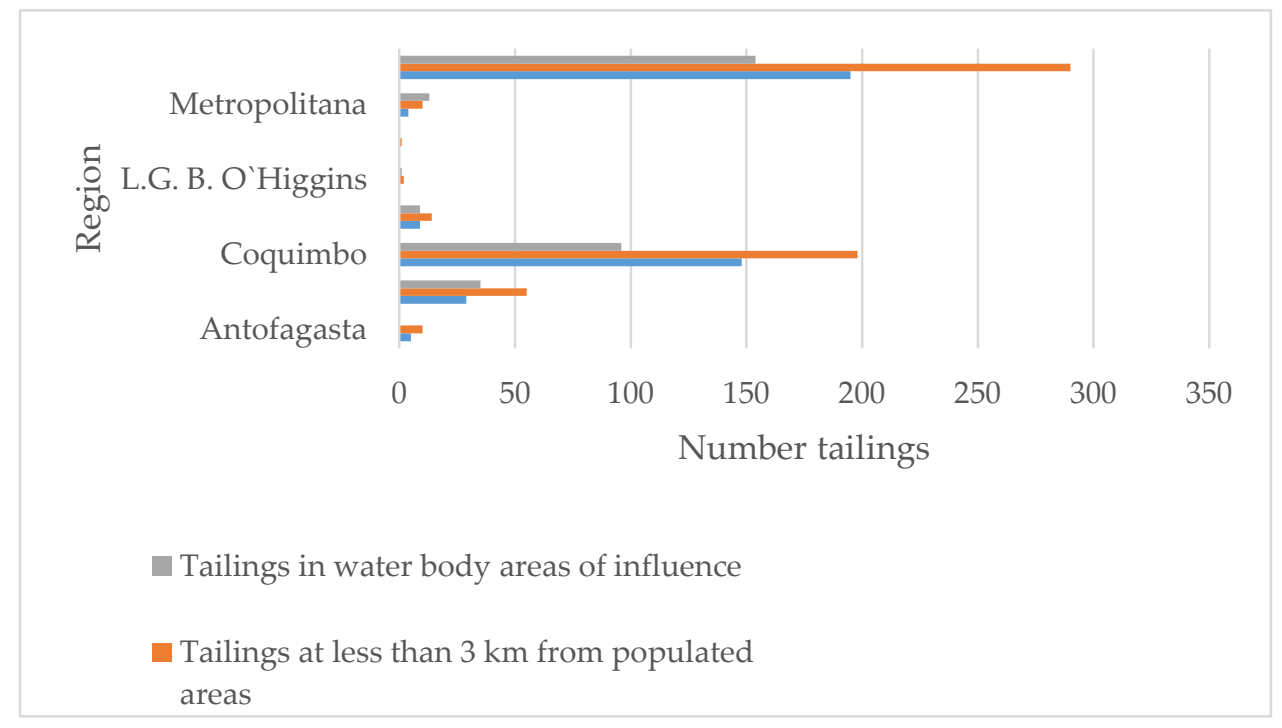

Figure 5. Distribution of tailings at less than $2-3 \mathrm{~km}$ from populates areas; tailings located close to water bodies (rivers, lakes, and estuaries). 


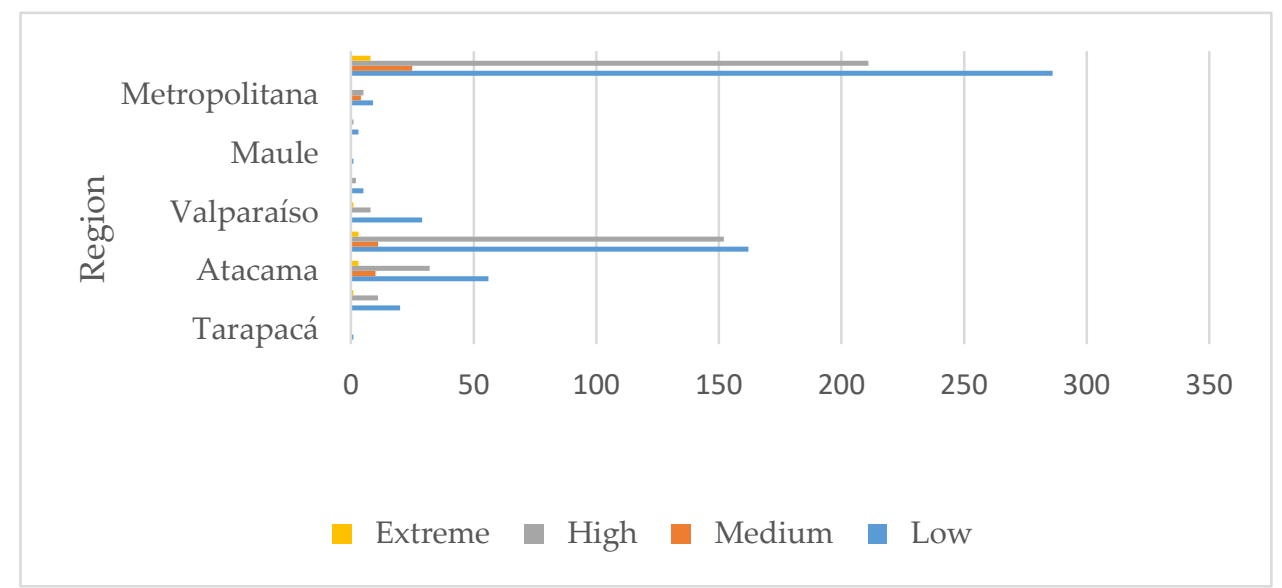

Figure 6. Regional distribution of tailings assessed according to heavy metals and closeness to populated areas.

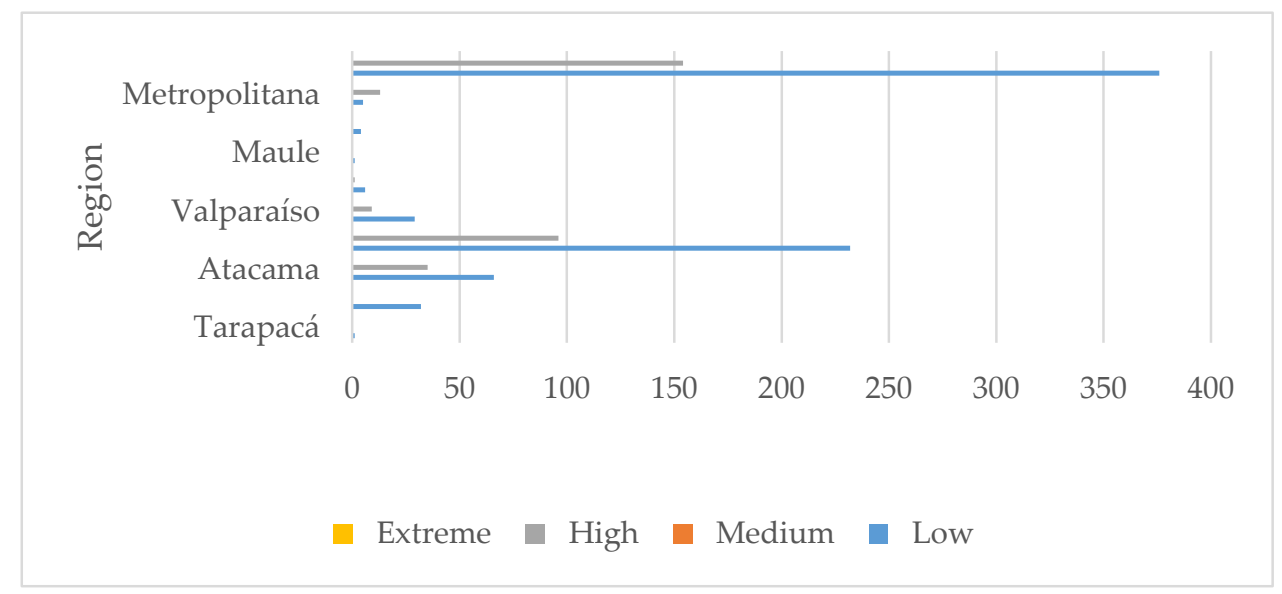

Figure 7. Distribution of regional tailings assessed according to heavy metals and water bodies.

\subsection{Tailings Prioritized as "Extreme"}

By considering heavy metal concentrations and closeness to populated areas and water bodies, tailings requiring special treatment were determined according to the following: (a) They show a high level of heavy metal contamination, (b) they are located within a 2-km radius close to a populated area, and/or (c) they are located within a water body area of influence. Twelve tailings classified as "extreme" were found, all of them located in the Illapel commune (Coquimbo Region). Five heavy metals exceed reference concentration values and are located at less than $2 \mathrm{~km}$ from populated areas and water bodies.

\subsection{Ecological Risk Analysis}

Hakanson's methodology [14] was used to determine metals that are environmentally risky. To do this, soil background values are needed ( $\mathrm{Cu} 134.7 \mathrm{~g} \mathrm{t}^{-1} ; \mathrm{Cr} 20.66 \mathrm{~g} \mathrm{t}^{-1} ; \mathrm{Ni} 50.68 \mathrm{~g} \mathrm{t}^{-1} ; \mathrm{Zn} 99.27 \mathrm{~g} \mathrm{t}^{-1} ; \mathrm{Pb}$ $7.881 \mathrm{~g} \mathrm{t}^{-1}$; As $\left.2.30 \mathrm{~g} \mathrm{t}^{-1} ; \mathrm{Cd} 1.508 \mathrm{~g} \mathrm{t}^{-1} ; \mathrm{Hg} 0.14 \mathrm{~g} \mathrm{t}^{-1}\right)$. The analysis using Hakanson's methodology revealed that the five deposits identified as Anta Colla 1, Anta Colla 2, California 0, Esperanza Dos, and NN3 show high potential ecological risk indexes (RIs) greater than 320 and, therefore, are qualified as "showing extremely high ecological risk", according to the criteria in Table 3. Figure 8 shows the location of four of them. 


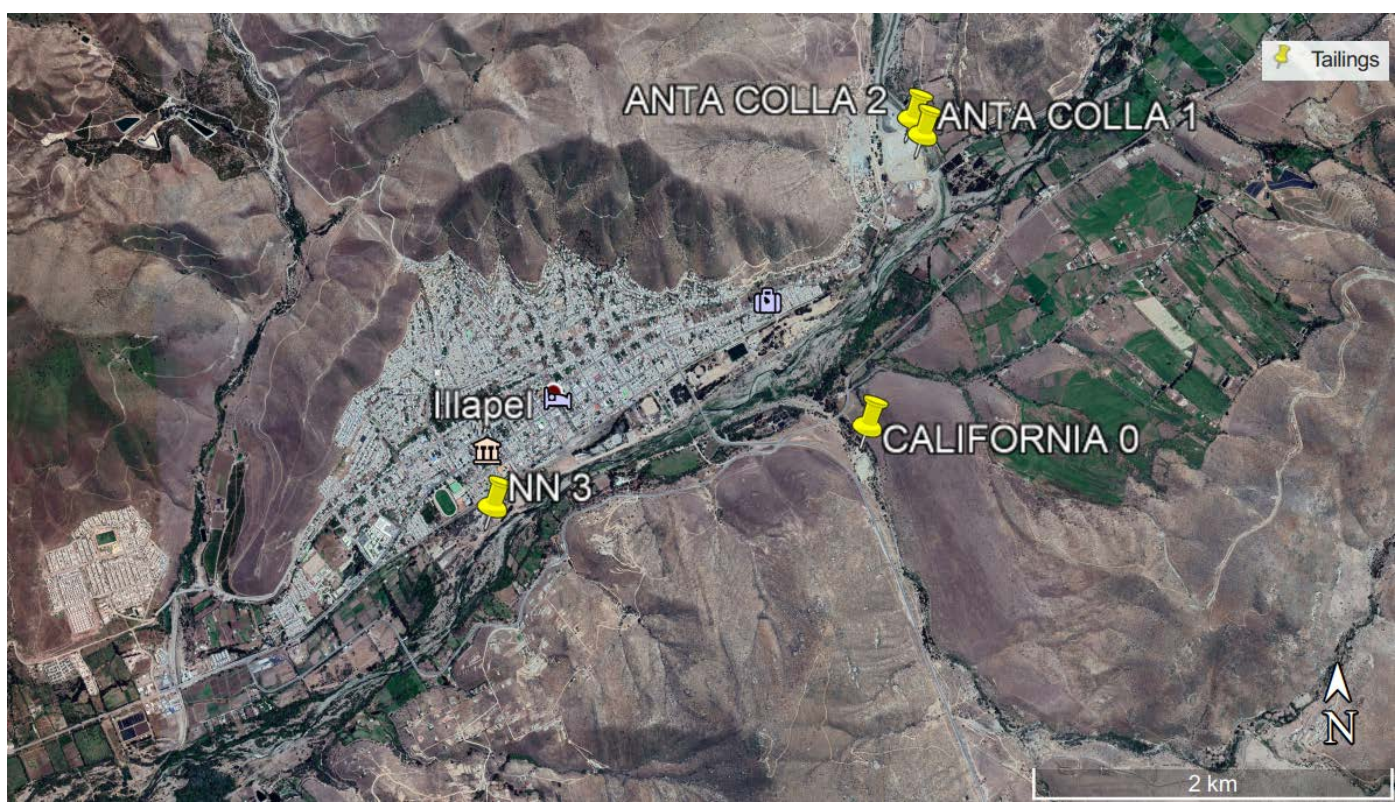

Figure 8. Tailings showing extremely high risk, according to Hakanson's methodology [14].

As shown in Figure 8, California 0 and Anta Colla 2 deposits are located close to populated areas. Hence, exposure to them cannot be controlled because their location makes it impossible to keep people away from the sites, the same for NN3 and Anta Colla 1 tailings located in the area. According to Illapel climatological data, rainfall is very low in summer months, while in winter (June and July), the average rainfall is $50 \mathrm{~mm}$. Rainfall is a risk because metals may infiltrate the soil and contaminate nearby or underground water if the soil is permeable, and there is no appropriate insulation. Soils on the lower area of the Choapa River basin are mainly characterized by highly permeable soils and limited capacity for agricultural use, while in the upper area, the soils have characteristics appropriate for culturing fruit trees. The city of Illapel is located at upper Choapa, so its soil is less permeable.

Table 7 shows the potential ecological risk index values and the ecological risk factor of each heavy metal per tailings, revealing that the heavy metal with the highest ecological risk factor is As, the lowest being $\mathrm{Zn}$, considering the average of the 12 critical deposits.

Table 7. Average heavy metal concentration values and potential ecological risk index for Illapel critical tailings.

\begin{tabular}{cccccccccc}
\hline Identification $^{\mathbf{1}}$ & \multicolumn{8}{c}{ Ecological Risk Factor $\mathbf{E}_{\mathbf{r}}^{\mathbf{i}}$} & \multicolumn{3}{c}{ Potential Ecological Risk Index } \\
\hline Name of tailing & $\mathbf{C u}$ & $\mathbf{C r}$ & $\mathbf{N i}$ & $\mathbf{Z n}$ & $\mathbf{P b}$ & $\mathbf{A s}$ & $\mathbf{C d}$ & $\mathbf{H g}$ & $\mathbf{R I}$ \\
\hline Anta Colla 2 & 53.4 & 5.6 & 9.2 & 0.7 & 460.4 & 1702.2 & 137.2 & 21.9 & 2391 \\
Anta Colla 1 & 64.9 & 5.5 & 8.9 & 0.7 & 442.6 & 1607.9 & 33.3 & 106.7 & 2271 \\
California 0 & 116.5 & 12.3 & 8.6 & 1.1 & 186.9 & 469.4 & 67.7 & 1280 & 2142 \\
California 2B & 11.5 & 6.9 & 7.5 & 0.5 & 24.1 & 40.0 & 135.8 & 24.8 & 251 \\
El Arenal & 42.3 & 5.4 & 7.9 & 2.5 & 60.1 & 40.0 & 77.8 & 48.6 & 586 \\
Esperanza Dos & 81.6 & 8.7 & 9.0 & 0.6 & 78.7 & 40.0 & 123.0 & 244.3 & 727 \\
NN 3 & 26.3 & 5.2 & 7.5 & 0.6 & 69.1 & 40.0 & 132.7 & 445.7 & 242 \\
Pluma de oro & 7.3 & 9.7 & 7.9 & 0.7 & 26.6 & 40.0 & 80.7 & 69.5 & 265 \\
San Jorge 1-2-3 & 31.8 & 7.3 & 6.7 & 0.9 & 22.6 & 40.0 & 123.3 & 32.4 & 246 \\
Tailings dam 0 & 35.0 & 11.3 & 9.6 & 1.1 & 50.4 & 40.0 & 70.6 & 27.9 & 274 \\
Tailings dam 1 & 45.3 & 5.6 & 7.1 & 1.0 & 31.5 & 40.0 & 103.3 & 40.0 & 263 \\
Tailings dam 2 & 35.2 & 6.0 & 7.6 & 1.0 & 40.4 & 40.0 & 100.1 & 32.4 & \\
\hline
\end{tabular}

${ }^{1}$ Identification according to National Geology and Mining Service (SERNAGEOMIN) [4].

According to Hakanson's ecological risk factor, the level of contamination was low for three of the twelve tailings assessed, that is, $\mathrm{Cr}, \mathrm{Ni}$, and $\mathrm{Zn}$. In Anta Colla 2, the level of contamination was medium for $\mathrm{Cu}$, low for $\mathrm{Hg}$, very high for $\mathrm{Cd}$, and extremely high for $\mathrm{Pb}$ and $\mathrm{As}$, the latter being 
recognized for their high toxicity. In Anta Colla 1, the level of contamination was medium for Cd, high for $\mathrm{Cu}$ and $\mathrm{Hg}$, and extremely high for $\mathrm{Pb}$ and $\mathrm{As}$, the same as above. In California 0 , the level of contamination was high for $\mathrm{Cu}$ and $\mathrm{Cd}$, very high for $\mathrm{Pb}$, and extremely high for $\mathrm{As}$ and $\mathrm{Hg}$. In California $2 \mathrm{~B}$, the level of contamination was low for $\mathrm{Cu}, \mathrm{Pb}$, and $\mathrm{Hg}$, medium for $\mathrm{As}$, and very high for Cd. In El Arenal, San Jorge 1-2-3, and Tailings Dams 0, 1, and 2, the level of contamination was medium for As and $\mathrm{Cu}$. In NN3 and Pluma de Oro, the level of contamination was low for $\mathrm{Cu}$ and medium for As. In Esperanza Dos, the level of contamination was high for $\mathrm{Cu}$ and medium for As. In Esperanza Dos and NN3, the level of contamination was extremely high for $\mathrm{Hg}$, while in El Arenal, San Jorge 1-2-3, and Tailings Dams 1 and 2, the level of contamination was medium for $\mathrm{Hg}$. In California 2B, Esperanza Dos, NN3, and San Jorge 1-2-3, the level of contamination was very high for Cd. In El Arenal, Pluma de Oro, and Tailings Dams 0, 1, and 2, the level of contamination was high. Five tailings fit into the category of "extremely high potential ecological risk", that is, Anta Colla 1, Anta Colla 2, California 0, Esperanza Dos, and NN3. The other seven tailings fit into the category of "very high potential ecological risk". These results indicate that the 12 tailings require intervention for their ecological and environmental risks. However, the order of priority is Anta Colla 2, Anta Colla 1, California 0, NN3, and Esperanza Dos.

\section{Conclusions}

This paper deals with a methodology to prioritize Chilean tailings according to their potential ecological and environmental risks. The application of this methodology shows that five tailings require urgent intervention in Chile; the heavy metals showing the greatest environmental risk being $\mathrm{As}, \mathrm{Cd}, \mathrm{Pb}$, and $\mathrm{Hg}$, which are recognized for their high toxicity.

The comparison of the three reference frameworks showed diverse criteria, thus making the analysis difficult. Only the tailings that do not require intervention, according to the Dutch, Canadian, and Australian reference frameworks, were discarded because they do not involve potential ecological and environmental risks. This allowed us to reduce the costs associated with a more thorough assessment. On the other hand, the application of Chilean criteria, although not compulsory, suggests Chilean soil conditions. Finally, this study reveals the need to count on background soil concentration values and also measurements of clay and organic materials for the tailings. These data will allow a clearer picture of the real risks associated with Chilean tailings.

Author Contributions: Conceptualization, E.J.L. and N.F.G.; methodology, E.J.L., I.L.M., D.A.P., and N.F.G.; validation, N.F.G. and R.J.R.; formal analysis, E.J.L. and R.J.R.; investigation, E.J.L., I.L.M., F.A.Á., R.J.R., D.A.P., and N.F.G.; data curation, F.A.Á. and D.A.P.; writing-original draft preparation, E.J.L.; writing-review and editing, E.J.L.; visualization, F.A.Á.; project administration, E.J.L. All authors have read and agreed to the published version of the manuscript.

Funding: This research was funded by "Rapid Implementation Projects-Pilot Scaling", Universidad Católica del Norte, Engineering Project 2030, 16EN12-71940.

Acknowledgments: The authors are thankful to "Rapid Implementation Projects-Pilot Scaling", Universidad Católica del Norte, Engineering Project 2030, 16EN12-71940, for the financial support of this project.

Conflicts of Interest: The authors declare no conflict of interest.

\section{References}

1. Castro, S.H.; Sánchez, M. Environmental viewpoint on small-scale copper, gold and silver mining in Chile. J. Clean. Prod. 2003, 11, 207-213. [CrossRef]

2. Ghorbani, Y.; Kuan, S.H. A review of sustainable development in the Chilean mining sector: Past, present and future. Int. J. Min. Recl. Environ. 2017, 31, 137-165. [CrossRef]

3. Wong-Pinto, L.S.; Menzies, A.; Ordóñez, J.I. Bionanomining: Biotechnological synthesis of metal nanoparticles from mining waste-Opportunity for sustainable management of mining environmental liabilities. Appl. Microbiol. Biotechnol. 2020, 104, 1859-1869. [CrossRef] [PubMed] 
4. SERNAGEOMIN. Geochemical Data from Tailing Deposits in Chile; National Service of Geology and Mining: Santiago, Chile, 2017. Available online: http://www.sernageomin.cl/mineriarelaves.php (accessed on 10 May 2017).

5. Garcia, P.; Knights, P.F.; Tilton, J.E. Labor productivity and comparative advantage in mining: The copper industry in Chile. Res. Policy 2001, 27, 97-105. [CrossRef]

6. Moreno-Maroto, J.M.; González-Corrochano, B.; Alonso-Azcárate, J.; García, C.M. A study on the valorization of a metallic ore mining tailing and its combination with polymeric wastes for lightweight aggregates production. J. Clean. Prod. 2019, 212, 997-1007. [CrossRef]

7. Araya, N.; Kraslawski, A.; Cisternas, L.A. Towards mine tailings valorization: Recovery of critical materials from Chilean mine tailings. J. Clean. Prod. 2020, 263, 121555. [CrossRef]

8. Lam, E.J.; Zetola, V.; Ramírez, Y.; Montofré, Í.L.; Pereira, F. Making Paving Stones from Copper Mine Tailings as Aggregates. Int. J. Environ. Res. Public Health 2020, 17, 2448. [CrossRef]

9. Esquenazi, E.L.; Norambuena, B.K.; Bacigalupo, Í.M.; Estay, M.G. Evaluation of soil intervention values in mine tailings in northern Chile. Peer] 2018, 6, e5879. [CrossRef]

10. GMPGSPPC. Guía Metodología para la Gestión de Suelos con Potencial Presencia de Contaminantes; Corporación de Fomentos de la Producción (CORFO) y Ministerio del Medio Ambiente: Santiago, Chile, 2012.

11. Alcalde, J.; Kelm, U.; Vergara, D. Historical assessment of metal recovery potential from old mine tailings: A study case for porphyry copper tailings, Chile. Miner. Eng. 2018, 127, 334-338. [CrossRef]

12. Casanova, M.; Salazar, O.; Seguel, O.; Luzio, W. Main features of Chilean soils. In The Soils of Chile; Springer: Dordrecht, The Netherlands, 2013; pp. 25-97. [CrossRef]

13. Nehdi, M.; Tariq, A. Stabilization of sulphidic mine tailings for prevention of metal release and acid drainage using cementitious materials: A review. J. Environ. Eng. Sci. 2007, 6, 423-436. [CrossRef]

14. Choi, W.H.; Lee, S.R.; Park, J.Y. Cement based solidification/stabilization of arsenic-contaminated mine tailings. Waste Manag. 2009, 29, 1766-1771. [CrossRef] [PubMed]

15. Elghali, A.; Benzaazoua, M.; Bussière, B.; Genty, T. In Situ Effectiveness of Alkaline and Cementitious Amendments to Stabilize Oxidized Acid-Generating Tailings. Minerals 2019, 9, 314. [CrossRef]

16. Perlroth, N.H.; Castelo Branco, C.W. Current knowledge of environmental exposure in children during the sensitive developmental periods. Rio Pediatr. 2017, 93, 17-27. [CrossRef]

17. Buckley, J.P.; Barrett, E.S.; Beamer, P.I.; Bennett, D.H.; Bloom, M.S.; Fennell, T.R.; Fry, R.C.; Funk, W.E.; Hamra, G.B.; Hecht, S.S.; et al. Opportunities for evaluating chemical exposures and child health in the United States: The Environmental influences on Child Health Outcomes (ECHO) Program. J. Expo. Sci. Environ. Epidemiol. 2020, 30, 397-419. [CrossRef]

18. Hakanson, L. An ecological risk index for aquatic pollution control. A sedimentological approach. Water Res. 1980, 14, 975-1001. [CrossRef]

19. Min, X.B.; Xie, X.D.; Chai, L.Y.; Liang, Y.J.; Mi, L.I.; Yong, K.E. Environmental availability and ecological risk assessment of heavy metals in zinc leaching residue. Trans. Nonferrous Met. Soc. China 2013, 23, 208-218. [CrossRef]

20. El Azhari, A.; Rhoujjati, A.; El Hachimi, M.L.; Ambrosi, J.P. Pollution and ecological risk assessment of heavy metals in the soil-plant system and the sediment-water column around a former $\mathrm{Pb} / \mathrm{Zn}$-mining area in NE Morocco. Ecotoxicol. Environ. Saf. 2017, 144, 464-474. [CrossRef]

21. Yao, D.X.; Meng, J.; Zhang, Z.G. Heavy metal pollution and potential ecological risk in reclaimed soils in Huainan mining area. J. Coal Sci. Eng. China 2010, 16, 316-319. [CrossRef]

22. Kerolli-Mustafa, M.; Fajković, H.; Rončević, S.; Ćurković, L. Assessment of metal risks from different depths of jarosite tailing waste of Trepça Zinc Industry, Kosovo based on BCR procedure. J. Geochem. Explor. 2015, 148, 161-168. [CrossRef]

23. Fei, J.C.; Min, X.B.; Wang, Z.X.; Pang, Z.H.; Liang, Y.J.; Ke, Y. Health and ecological risk assessment of heavy metals pollution in an antimony mining region: A case study from South China. Environ. Sci. Pollut. Res. 2017, 24, 27573-27586. [CrossRef]

24. Wang, Y.; Dong, J.H. Potential ecological risk assessment of filling reclaimed soils polluted by heavy metals in mining area. J. China Coal Soc. 2009, 34, 650-655.

25. Sulaiman, M.B.; Salawu, K.; Barambu, A.U. Assessment of Concentrations and Ecological Risk of Heavy Metals at Resident and Remediated Soils of Uncontrolled Mining Site at Dareta Village, Zamfara, Nigeria. J. Appl. Sci. Environ. Manag. 2019, 23, 187-193. [CrossRef] 
26. Canadian Council of Ministers of the Environment. Canadian Soil Quality Guidelines for the Protection of Environmental and Human Health; Canadian Council of Ministers of the Environment: Winnipeg, MB, Canada, 2007.

27. National Environmental Protection Council. Assessment of Site Contamination: Schedule B (7a) Guideline on Health Based Investigation Levels; Environment Protection and Heritage Council: Canberra, ACT, Australia, 1999.

28. Dutch Ministry of Housing, Spatial Planning and Environment. Circular Target Values and Intervention Values for Soil Remediation; Dutch Ministry of Housing, Spatial Planning and Environment: Hague, The Netherlands, 2000.

29. Rueda, S.G.; Rodríguez, V.J.A.; Madriñán, M.R. Metodologías para establecer valores de referencia de metales pesados en suelos agrícolas perspectivas para Colombia. Acta Agronómica 2011, 60, 203-217.

30. Stouraiti, C.; Xenidis, A.; Paspaliaris, I. Reduction of $\mathrm{Pb}, \mathrm{Zn}$ and $\mathrm{Cd}$ availability from tailings and contaminated soils by the application of lignite fly ash. Water Air Soil Pollut. 2002, 137, 247-265. [CrossRef]

31. Conesa, H.M.; Faz, Á.; Arnaldos, R. Initial studies for the phytostabilization of a mine tailing from the Cartagena-La Union Mining District (SE Spain). Chemosphere 2007, 66, 38-44. [CrossRef]

32. Lamont, B.B. Mineral nutrient relations in Mediterranean regions of California, Chile, and Australia. In Ecology and Biogeography of Mediterranean Ecosystems in Chile; Arroya, M.T., Zedler, P.H., Fox, M.D., Eds.; Springer: New York, NY, USA, 1995; pp. 211-235.

33. Lu, H.; Li, Z.; Fu, S.; Méndez, A.; Gascó, G.; Paz-Ferreiro, J. Combining phytoextraction and biochar addition improves soil biochemical properties in a soil contaminated with Cd. Chemosphere 2015, 119, 209-216. [CrossRef]

34. Ashrafi, M.; Mohamad, S.; Yusoff, I.; Hamid, F.S. Immobilization of Pb, Cd, and Zn in a contaminated soil using eggshell and banana stem amendments: Metal leachability and a sequential extraction study. Environ. Sci. Pollut. Res. 2015, 22, 223-230. [CrossRef]

35. Tanić, M.N.; Ćujić, M.R.; Gajić, B.A.; Daković, M.Z.; Dragović, S.D. Content of the potentially harmful elements in soil around the major coal-fired power plant in Serbia: Relation to soil characteristics, evaluation of spatial distribution and source apportionment. Environ. Earth Sci. 2018, 77, 28. [CrossRef]

36. Bünemann, E.K.; Bongiorno, G.; Bai, Z.; Creamer, R.E.; De Deyn, G.; de Goede, R.; Fleskens, L.; Geissen, V.; Kuyper, T.W.; Mäder, P.; et al. Soil quality-A critical review. Soil Biol. Biochem. 2018, 120, 105-125. [CrossRef]

37. Esquenazi, E.J.L.; Norambuena, B.F.K.; Bacigalupo, Í.L.M.; Estay, M.E.G. Necessity of intervention policies for tailings identified in the Antofagasta Region, Chile. Rev. Int. Contam. Ambie. 2019, 35, 515-539. [CrossRef]

38. Abuduwaili, J.; Zhang, Z.; Jiang, F. Assessment of the distribution, sources and potential ecological risk of heavy metals in the dry surface sediment of Aibi Lake in Northwest China. PLoS ONE 2015, 10, e0120001. [CrossRef] [PubMed]

39. Soliman, N.F.; Nasr, S.M.; Okbah, M.A. Potential ecological risk of heavy metals in sediments from the Mediterranean coast, Egypt. J. Environ. Health Sci. Eng. 2015, 13, 70. [CrossRef]

40. Qingjie, G.; Jun, D.; Yunchuan, X.; Qingfei, W.; Liqiang, Y. Calculating pollution indices by heavy metals in ecological geochemistry assessment and a case study in parks of Beijing. J. Chin. Univ. Geosci. 2008, 19, 230-241. [CrossRef]

41. Jiang, X.; Lu, W.X.; Zhao, H.Q.; Yang, Q.C.; Yang, Z.P. Potential ecological risk assessment and prediction of soil heavy-metal pollution around coal gangue dump. Nat. Hazards Earth Syst. Sci. 2014, 14, 1599-1610. [CrossRef]

(C) 2020 by the authors. Licensee MDPI, Basel, Switzerland. This article is an open access article distributed under the terms and conditions of the Creative Commons Attribution (CC BY) license (http://creativecommons.org/licenses/by/4.0/). 